\title{
Comunhão com o homem comum
}

Fraya Frehse

$O^{\circ}$ QUE poderia haver de comum entre a segunda edição revista e ampliada de um livro de sociologia da vida cotidiana lançado pela primeira vez em 2000 e relançado em 2008, e um CD embebido de acordes de viola caipira vindo a público no final de 2007? Seria o forte laço de amizade que une os seus dois autores, respectivamente, José de Souza Martins, sociólogo e professor do Departamento de Sociologia da USP, e Ivan Vilela, violeiro e professor do Departamento de Música da mesma Universidade? Outra opção: o interesse de ambos por decifrar o chamado "Brasil profundo" - no primeiro caso, em termos sociológicos; no segundo, musicalmente. Se as duas possibilidades certamente se aplicam, gostaria, aqui, de explorar uma terceira. $\mathrm{O}$ que esse livro e o CD compartilham também é a comunhão que cada um dos autores estabelece com o homem comum que somos todos, leitores ou não de livros como esse, apreciadores ou não de violas como a de Ivan Vilela, em nossa vida de todo dia, no Brasil deste início de século XXI. ${ }^{1}$

Basta ler as primeiras linhas do livro, basta ouvir os primeiros acordes do CD: o que, em cada um, nos toca para além do intelecto, da razão, é aquilo que sensibiliza, faz chorar e rir o homem simples que habita em nós. $\mathrm{E}$ isso, por mais que a vida cotidiana, cada vez mais constrangida pela cotidianidade que vivemos na cidade de São Paulo - e não só nela, porém ainda em outros locais do Brasil - nos dias de hoje, se interponha com vigor crescente entre o que somos e o que pensamos ser. $\mathrm{O}$ que o livro e o CD propõem, cada um a seu modo, são pontes, criativas pontes para esse fosso entre nós e nós. Advém daí que, ao ler e ao ouvir, nos reencontramos com o que de nós, na rotina, quase nem sabemos mais existir. As pontes conduzem ao homem comum.

É, de fato, ele o grande protagonista do livro e do CD. Ivan Vilela o puxa para o palco já por meio do instrumento que toca: a secular viola caipira. Ela já fez chorar não só o violeiro, não só sua amada, não só a população do campo, mas inclusive - e, brevemente, um depoimento pessoal - o meu avô imigrante, urbanita alemão pobre que chegou ao Brasil em 1924 e que sempre ficava com os olhos marejados, ao ouvir um dos muitos LP de Inezita Barroso que buscou colecionar, morador de São Paulo, ao longo de toda a sua vida.

Uma vez no palco, o homem simples dança a "Valsinha" de Vinícius de Morais e Chico Buarque tal qual reinventada por Ivan Vilela. Ele vira também "Eleanor Rigby", vira "Moreninha" e/ou "Pescador", títulos de outras das várias músicas do $\mathrm{CD}$. Embalado pelo "Ponteio" de Edu Lobo e de Capinam imaginado por Ivan, o homem simples "chora" com a viola que ninguém como ele, às vezes travestido de Ivan-George Harrison, sabe fazer chorar: "While my guitar gently weeps"... Mas o homem simples também se emociona ao discernir, numa árvore imaginária ou não, um "Passarim". Recorda-se, assim, de antigas "carreiras" e da tristeza sem fim de uma "viola quebrada". 
Diante da emoção que emana dessas "Dez cordas" que unem, numa só unidade, o diverso do popular e do erudito, do tradicional e do moderno, do rural e do urbano, eis que nós, outros homens comuns tão pobres de tempo, de repente achamos tempo para nos deixar tocar. Tempo para, pela mediação dessas toadas, nos reconciliar com aquele que, em meio à vida cotidianizada dos atuais tempos de capitalismo globalizado, nem bem mais bem sabemos que também somos.

De fato, nesse CD e nesse livro o homem comum merece toda a claridade do "Luzeiro", outro título de Almir Sater que as cordas de Ivan reteceram. Luzeiro para o qual José de Souza Martins, em $A$ sociabilidade do homem simples, abre espaço através de sua já conhecida e notável imaginação sociológica. Imaginação sociológica notável por vários aspectos, mas também pela maneira como consegue conjugar competência teórica e metodológica e sensibilidade etnográfica para trazer para o centro da reflexão sociológica justamente o homem comum.

Tal perspectiva não é nem um pouco comum na sociologia. Se já não o era há quase dez anos, quando o livro foi lançado pela primeira vez, infelizmente ainda o é pouco neste início de século XXI. Difícil, a equação entre teoria e empiria, sobretudo num país como o nosso. Diante da complexidade que a "sociabilidade do homem simples" brasileiro oferece o olhar sociológico, é grande a tentação de deixá-lo "para lá", na (vã) tentativa de resguardar, das vicissitudes sociais e culturais brasileiras, a coerência das grandes teorias européias ou norte-americanas. O quanto do projeto histórico da sociologia assim se perde fica obliterado para o homem comum brasileiro que o soció- logo ou a socióloga não deixa, também ele ou ela, de ser, ao produzir sociologia no Brasil. Em seu livro, Martins assume precisamente essa complexidade como pretexto e desafio sociológico. $\mathrm{O}$ que implica inevitavelmente assumir como objeto de ponderação - e crítica - a própria sociologia.

Se em Ivan Vilela o homem comum dança, chora, relembra, se emociona, ele é exatamente aquele que passeia pelas páginas de $A$ sociabilidade do homem simples. Só que aqui esse é contemplado pelas relações sociais que o envolvem e por meio das quais ele se constitui como tal. É enfocado por meio do embate dialético que o seu imaginário trava dia a dia com a sua imaginação. É observado, enfim, por meio da história que ele faz na história, e da cultura da qual ele é produto e produtor. É o que assegura que o passeio desse homem comum pelo livro seja movimentado, socialmente. Com freqüência ele se encontra em companhia de terceiros: sua família, seus vizinhos, seus estranhos da vigília e do sonho, seus Outros de casa e da rua, seus companheiros de ônibus e de estrada. Isso quando ele não é acompanhado por grupos mais amplos - de índios Parkatejê, de movimentos sociais como o dos Trabalhadores Rurais Sem Terra - e também por grupos mais abstratos, como o movimento literário modernista no Brasil e na América Latina.

Como cercar analiticamente toda essa pletora de gente em seu cotidiano e manter-se próximo dela em meio à inevitabilidade de teorização, crucial para uma compreensão propriamente sociológica da "sociabilidade do homem simples"? Levando, como faz Martins, absolutamente a sério o aparentemente insignificante, o irrelevante da vida de 


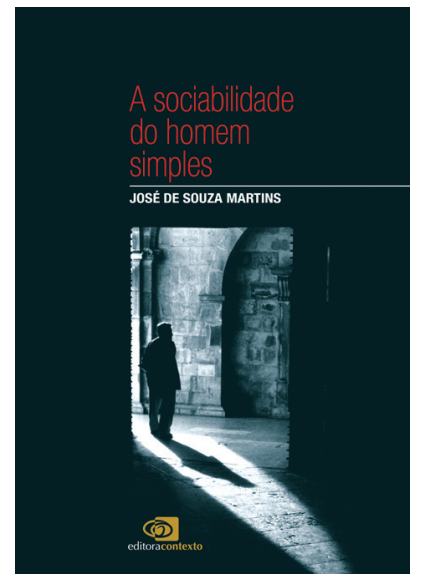

MARTINS, José de Souza $A$ sociabilidade do homem simples. 2.ed. rev. e ampl. São Paulo: Contexto, 2008. 171p.

todo dia, aquilo que à primeira vista é totalmente incoerente - e, por isso mesmo, tão incômodo ao olhar sociológico mais desavisado.

Por que o enfoque? Porque Martins entende que "a explicação do todo concreto" fica "incompleta e pobre se não passa pela mediação do insignificante" (p.11). Entender a sociedade e a história depende de se entender como ambas se expressam - e são feitas - na vida cotidiana. Ou, como diz Martins: "É na vida cotidiana que a História se desvenda ou se oculta” (p.12). Vem daí que o homem comum que vagueia pelo livro conta também com a companhia dos olhares sempre atentos dos interlocutores teóricos privilegiados do autor: as obras de Florestan Fernandes e de seus alunos, a obra de Antonio Candido e de seus alunos, a obra de Karl Marx e, em particular, a de Henri Lefebvre. Em cada um desses pensadores, de modos diversos, a busca por uma compreensão sociológica enraizada - enraizada não apenas empírica, mas historicamente.

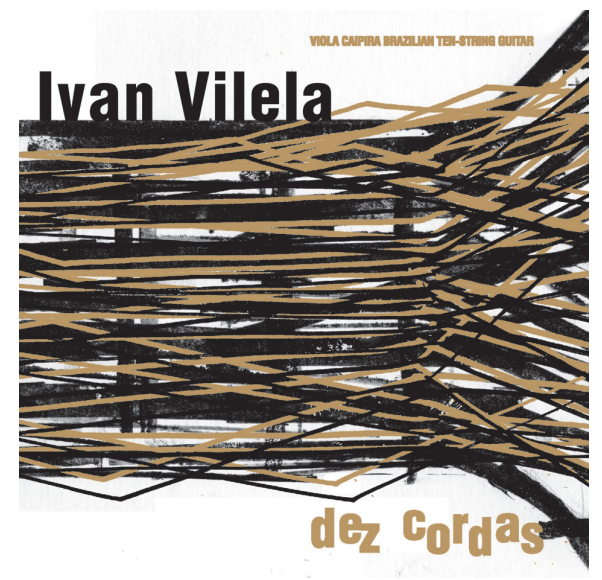

VILELA, Ivan. Dez cordas. Viola caipira - Brazilian Ten-String Guitar. CD-ROM. Kalamata, 2007.

Por tudo isso, o passeio que o livro propõe se inicia numa travessia liminar como aquelas, profundamente reveladoras, de Guimarães Rosa. Travessia essa que não deixa de ser uma vereda estreita como aquela mesma onde se apeia, para tocar, o violeiro de Ivan Vilela. O leitor é convidado a conhecer primeiramente essa travessia, sempre inconclusa, que marca o nosso modo brasileiro - e latino-americano - de ser e de viver a modernidade, a fim de poder, num segundo momento, compreender por que é tamanha a riqueza interpretativa que especificamente o senso comum, modalidade de conhecimento privilegiada do homem simples, oferece ao pensamento sociológico. Foi essa a estratégia narrativa que Martins escolheu para levar o leitor a descobrir sociologicamente o homem comum que mora dentro dele mesmo.

Já próximo desse homem, o leitor pode, nos capítulos seguintes, tornar-se seu companheiro pelas veredas. Assim pode compreender melhor algumas sea- 
ras que são mediações pelas quais esse homem se achega e afasta de si dia a dia, no cotidiano cada vez mais tomado pela cotidianidade em que nos movemos todos, no Brasil da atualidade. Tomamos contato com os processos sociais e históricos mais amplos que os nossos sonhos ocultam e revelam; compreendemos por que vida cotidiana e vida privada não são a mesma coisa; por que sociologicamente o nosso tempo é prenhe de temporalidades históricas; por que, enfim, levar em consideração tudo isso carrega em si tantas potencialidades para uma compreensão enraizada, "não alienada”, daquilo que somos, cada um de nós, no Brasil de hoje.

Na segunda parte do livro, é o fazer sociológico do próprio Martins que se torna objeto de enraizamento social e histórico. As duas entrevistas concedidas pelo autor trazem para o primeiro plano justamente o homem comum que também Martins é. Refiro-me ao filho do subúrbio paulistano, filho de imigrantes ibéricos pobres, que fez da sociologia muito mais do que um ofício. Fez dela um modo de estar no mundo, um modo privilegiado de vivê-lo e de pensá-lo. Um modo de, pela mediação da sociologia, fazer história e, assim, fazer-se humano na história.

Marcados por tais características, o livro e o CD abrigam uma intimidade com o homem comum que estimula - e assim finalizo esta reflexão - uma pergunta marota: Como é possível tanta proximidade com os rincões do mundo cotidiano de cada um e de todos nós, sendo Martins e Ivan também intelectuais? Talvez porque, acima de tudo, Martins e Ivan tenham conseguido, cada um à sua maneira, não apenas reencontrar, mas apossar-se efetivamente - em casa, na rua e na academia, em seus textos e músicas - do homem comum que eles também são.

Nota

1 Desenvolvi pela primeira vez este argumento por ocasião de um convite que me foi feito, de apresentar publicamente o livro e o CD durante o evento de lançamento conjunto de ambos, na paulistana Livraria da Vila, em 3 de março de 2008.

Fraya Frehse é professora doutora do Departamento de Sociologia da USP e pesquisadora associada do Núcleo de Antropologia Urbana da mesma Universidade. @-fraya@usp.br 